\title{
Retinoblastoma: experience of a referral center in the North Region of Portugal
}

\author{
This article was published in the following Dove Press journal: \\ Clinical Ophthalmology \\ 20 May 2014 \\ Number of times this article has been viewed
}

\author{
RA da Rocha-Bastos' \\ JR Araújo' \\ RS Silva ${ }^{2}$ \\ MJ Gil-da-Costa ${ }^{2}$ \\ E Brandão' \\ NJ Farinha ${ }^{2,3}$ \\ F Falcão-Reis ${ }^{1,4}$ \\ T Dinah-Bragança'
}

'Department of Ophthalmology, Hospital São João, ${ }^{2}$ Hematology and Oncology Unit, Pediatric Hospital, Hospital São João, ${ }^{3}$ Pediatrics

Department, Faculty of Medicine, University of Porto, ${ }^{4}$ Department of Sense Organs, Faculty of Medicine,

University of Porto, Porto, Portugal

Correspondence: Ricardo António da Rocha-Bastos

Department of Ophthalmology, Hospital São João, Alameda Prof Hernâni Monteiro, 4200-319 Porto, Portugal

Tel +35I 917475010

Email rarbastos@gmail.com
Purpose: To describe the experience of the Ophthalmology Department of Hospital São João (HSJ), a tertiary health care center in North Region, Portugal, in terms of the diagnosis, treatment, and follow-up of retinoblastoma.

Methods: This was a retrospective study of patients diagnosed with retinoblastoma in Hospital São João, between 1978 and 2012.

Results: Fifty patients with retinoblastoma were evaluated in our institution between 1978 and 2012. Four patients were excluded due to loss of follow-up. Among the 46 retinoblastoma cases, $33(71.7 \%)$ were unilateral and $13(28.3 \%)$ bilateral, with a mean age at diagnosis of 22.19 months and 6.92 months, respectively $(P<0.001)$. Leukocoria was the most common presenting sign (36.9\%), followed by strabismus (19.6\%), a combination of leukocoria and strabismus (8.7\%), and buphthalmia (2.2\%). Between 1978 and 1992, nine retinoblastoma cases were referred to our hospital, all of them unilateral, and, in each case, enucleation was performed, with or without salvage therapy. Between 1993 and 2012, 18 eyes with retinoblastoma were successfully managed with conservative treatment.

Conclusion: Demographic results were generally coincident with previous reports. It is crucial to screen leukocoria in pediatric practice, even in asymptomatic children. The outcome of retinoblastoma treatment in our hospital is similar to other series in developed countries.

Keywords: retinoblastoma, leukocoria, strabismus, enucleation, pediatric cancer

\section{Introduction}

Retinoblastoma is the most frequent intraocular malignancy in childhood, and represents about $3 \%$ of all pediatric cancers. ${ }^{1}$ Its incidence is constant worldwide, at one case per 15,000 to 20,000 live births, corresponding to about 9,000 cases every year. ${ }^{2}$ However, different birth rates and availability of health care generate very different prevalence, mortality rates and disease burden in developed versus undeveloped countries. Dimaras et al reported that about $40 \%-70 \%$ of children with retinoblastoma die in Asia and Africa, compared with 3\%-5\% in Europe, Canada, and the USA. ${ }^{3}$

Despite these discrepancies, retinoblastoma remains the pediatric cancer with the highest rates of survival in the 21 st century. ${ }^{4}$ Concerning retinoblastoma treatment, huge improvements have been observed in the last few decades toward the three goals of saving the patient's life, eye, and vision. This remarkable evolution relies on progressively earlier diagnosis, correct staging, and the development of effective conservative treatment options.

This study describes the experience of Hospital São João (HSJ), a central referral university hospital in northwestern Portugal, in the diagnosis, treatment, and follow-up of retinoblastoma, and analyses the improvements made in recent years. 


\section{Patients and methods}

The research reported here was a retrospective study in which we reviewed the clinical files of patients diagnosed with retinoblastoma referred to HSJ between 1978 and 2012.

Diagnosis of retinoblastoma was made by an ocular oncologist, using indirect ophthalmoscopy under general anesthesia with maximally dilated pupil. Anterior segment assessment was performed using the surgical microscope or the slit lamp, according to patient cooperation. B-scan ultrasonography was used to determine tumor dimensions, and computerized tomography and/or magnetic resonance imaging of the orbits and brain were performed in each patient. In selected patients, bone scan, lumbar puncture, and bone-marrow aspirates were performed to evaluate metastatic involvement.

All cases were simultaneously evaluated by pediatric oncologists from the Pediatric Hematology and Oncology Unit of the hospital.

From 1993, all local conservative treatments were performed at the Centre Ophthalmic Jules Gonin in Lausanne, Switzerland.

Patients were staged according to Reese and Ellsworth's grading system ${ }^{5}$ and divided into groups: Group I when a solitary tumor (Group Ia) or multiple tumors (Group Ib) of $\leq 4$ disc diameter (DD) were found at or behind the equator; Group II when a solitary tumor (Group IIa) or multiple tumors (Group IIb) of 4-10 DD in size were found at or behind the equator; Group IIIa when a lesion was found anterior to the equator; Group IIIb when a solitary tumor of 10 DD was found posterior to the equator; Group IVa when multiple tumors were found, some of them $>10$ DD in size; Group IVb when any lesion was found anterior to ora serrata; Group Va when a massive tumor involved $\geq 50 \%$ of the retina; and Group $\mathrm{Vb}$ when vitreous seeding was found.
Statistical analysis was performed using SPSS software (v 20.0; IBM Corporation, Armonk, NY, USA). Descriptive statistics for each variable were obtained. For continuous variables, means were compared using Student's $t$-tests and a $P$-value of $<0.05$ was regarded as significant.

\section{Results}

Fifty patients with retinoblastoma were evaluated in our institution between 1978 and 2012. Four patients were excluded from the analysis due to loss of follow-up. The male to female ratio was $1: 1$, and the mean follow-up period was 12 years (range $1-33$ years).

From a total of 46 retinoblastoma cases (59 eyes), 33 (71.7\%) were unilateral and $13(28.3 \%)$ were bilateral. Mean age at diagnosis was 22.19 months for unilateral retinoblastomas versus 6.92 months for bilateral cases, and this difference achieved statistical significance $(P<0.001$; Table 1$)$.

First presenting sign was determined in 31 out of 44 patients (in three patients the diagnosis was made by prenatal genetic screening according to familial history of bilateral retinoblastoma; in 12 cases first presenting sign was not clearly referred to in the medical notes). Leukocoria was found in $36.9 \%$ of cases, followed by strabismus (19.6\%), combination of leukocoria and strabismus $(8.7 \%)$, and buphthalmia (2.2\%). Mean time-interval between the first clinical sign and the diagnosis was recorded in 20 cases, being 4.4 months and 2.0 months for unilateral and bilateral retinoblastoma, respectively.

Retinoblastoma staging of the patients is presented in Table 2. No information was available concerning the nine patients treated between 1978 and 1992. Most unilateral retinoblastomas presented with advanced disease (57.6\% stage IV-V versus $15.1 \%$ stage I-III). Conversely, half of

Table I General comparison between unilateral and bilateral retinoblastoma patients

\begin{tabular}{llll}
\hline Characteristic & Unilateral retinoblastoma & Bilateral retinoblastoma & Total, N (\%) \\
\hline Sex & & & $23(50.0)$ \\
Male & 16 & 7 & $23(50.0)$ \\
Female & 17 & 6 & $46(100.0)$ \\
Total, N (\%) & $33(71.7)$ & $13(28.3)$ & $6.92, P<0.00$ I \\
Mean age at diagnosis (months) & 22.19 & 2.0 & $17(36.9)$ \\
Diagnosis lag (months)* & 4.4 & & $9(19.6)$ \\
Presenting sign(s) & & & $4(8.7)$ \\
Leukocoria & & & $1(2.2)$ \\
Strabismus & & & $15(32.6)$ \\
Leukocoria + strabismus & & & \\
Buphthalmia & & & \\
N/A & & & \\
\hline
\end{tabular}

Notes: *"Diagnosis lag" refers to the time interval between the first clinical signs and diagnosis; data available for 20 patients. Abbreviations: \%, relative frequency; N, absolute frequency; N/A, not applicable. 
Table 2 Staging of 59 eyes with retinoblastoma according to Reese-Ellsworth classification

\begin{tabular}{lllll}
\hline Laterality & Stage I-III, N (\%) & Stage IV-V, N (\%) & N/A, N (\%) & Total \\
\hline Unilateral & $5(I 5 . I)$ & $19(57.6)$ & $9(27.3)$ & $33(100.0)$ \\
Bilateral & $13(50.0)$ & $13(50.0)$ & $0(0.0)$ & $26(100.0)$ \\
\hline
\end{tabular}

Abbreviations: \%, relative frequency; $\mathrm{N}$, absolute frequency; N/A, information not available.

bilateral retinoblastomas were classified as stage I-III and half as stage IV-V.

Two different time schedules were considered with regard to the treatment analysis. Between 1978 and 1992, nine retinoblastoma cases were referred to our hospital (Table 3). All were unilateral and enucleation was performed in each case, with or without adjuvant treatment, according to high-risk features such as massive choroidal involvement or involvement of the sclera or optic nerve beyond the lamina cribrosa. During that period, external beam radiation therapy (EBRT) was performed in one patient, and no patient received chemotherapy.

In 1993, an Ocular Oncology Unit was created in our hospital and close cooperation began between the Ophthalmology Department, our Pediatric Hematology and Oncology Unit, and the Centre Ophthalmic Jules Gonin in Lausanne, Switzerland. Different conservative treatments became available, such as chemoreduction, transpupillary thermotherapy, cryotherapy, laser phototherapy (xenon and argon), brachytherapy, targeted intra-arterial melphalan chemotherapy, and intravitreal injection of melphalan (Tables 4 and 5). From 2005, no patient was treated with EBRT.

Between 1993 and 2012, half of the unilateral retinoblastomas were treated by enucleation alone. In eight additional cases, salvage therapy was performed after enucleation. Conservative treatment was attempted in four cases, being successful in two. Most bilateral retinoblastomas (61.5\%) were treated by unilateral enucleation and contralateral conservative treatment. Four patients $(30.8 \%)$ were treated with conservative therapy alone and one case needed bilateral enucleation. Between 1993 and 2012, 18 out of 50 eyes (36\%) with retinoblastoma were successfully managed by conservative therapy. The best-corrected visual acuity of these eyes was measurable in 12 cases (Table 6). Three patients with bilateral retinoblastoma were too young to cooperate in visual acuity measurement.
During the follow-up period, two patients developed secondary malignancies, both of which were sarcomas (an osteosarcoma and an Ewing sarcoma), one with unilateral and other with baseline bilateral retinoblastoma.

Three patients had a familial history of retinoblastoma, and in these cases a mutation in the $R b 1$ gene was identified.

One patient died during the follow-up period, a case of a stage $\mathrm{V}$ unilateral retinoblastoma, treated with enucleation, chemotherapy, and radiotherapy (due to choroidal and optic nerve invasion). The patient developed massive central nervous system dissemination.

\section{Discussion}

The demographic results of this study were coincident with previous reports concerning retinoblastoma laterality, sex distribution, and age of diagnosis. However, the age at diagnosis of unilateral and bilateral retinoblastoma patients found in our series was slightly lower than that reported in studies from North America and Europe (22.19 and 6.92 months, respectively). ${ }^{6-10}$ The statistically different age of diagnosis between unilateral and bilateral retinoblastomas reflects the known concepts of germ-line $R b 1$ gene mutation in the latter and the "two-hit" model classically described for this malignancy. ${ }^{11}$

Leukocoria was the most frequent presenting sign described by parents and referring doctors. This is the most common presenting sign of retinoblastoma in the USA and other developed countries, whereas in developing countries the tumor is often detected in an enlarged eye with locally invasive disease. ${ }^{12-14}$ Leukocoria, although not exclusive of retinoblastoma, is an important marker of curable disease. ${ }^{3}$ Even strabismus, the second most common presenting sign, typically represents more advanced disease or, at least, macular involvement of the tumor, which indicates a worse functional outcome. Therefore, it becomes crucial for every doctor

Table 3 Retinoblastoma treatment between 1978 and 1992

\begin{tabular}{lllll}
\hline Retinoblastoma & Frequency, N (\%) & Enucleation, N (\%) & Enucleation + EBRT, N (\%) & Conservative treatment, N (\%) \\
\hline Unilateral & $9(100.0)$ & $8(88.9)$ & I (II.I) & 0 \\
Bilateral & 0 & 0 & 0 & 0 \\
\hline
\end{tabular}

Abbreviations: \%, relative frequency; EBRT, external beam radiotherapy; $\mathrm{N}$, absolute frequency. 
Table 4 Treatment of unilateral retinoblastoma between 1993 and 2012

\begin{tabular}{llllll}
\hline Retinoblastoma & $\begin{array}{l}\text { Frequency, } \\
\mathbf{N}\end{array}$ & $\begin{array}{l}\text { Enucleation, } \\
\mathbf{N}(\%)\end{array}$ & $\begin{array}{l}\text { Enucleation + adjuvant } \\
\text { treatment,* N (\%) }\end{array}$ & $\begin{array}{l}\text { Conservative } \\
\text { treatment, ** N (\%) }\end{array}$ & $\begin{array}{l}\text { Secondary } \\
\text { enucleation, *** N (\%) }\end{array}$ \\
\hline Unilateral & 24 & $12(50.0)$ & $8(33.3)$ & $2(8.3)$ & $2(8.3)$ \\
\hline
\end{tabular}

Notes: *Adjunctive treatment: chemotherapy or EBRT (not performed since 2005); **conservative treatment options available: chemoreduction, thermochemotherapy, transpupillary thermotherapy, cryotherapy, brachytherapy, laser phototherapy (xenon and argon), targeted intra-arterial melphalan chemotherapy and intravitreal injection of melphalan; ***enucleation following failure of conservative treatment.

Abbreviations: \%, relative frequency; EBRT, external beam radiotherapy; $\mathrm{N}$, absolute frequency.

to search for leukocoria in pediatric practice, even in asymptomatic children. It is also of extreme importance to support educational campaigns for the general population, promoting public awareness of retinoblastoma and to the diverse signs and symptoms that allow its early detection, such as those campaigns undertaken in Honduras and Kenya.,15

The Reese-Ellsworth grading system, created in the 1960 s, has been widely used to predict the outcome of retinoblastoma patients treated with EBRT. ${ }^{5}$ However, as chemotherapy gradually replaced radiotherapy, new staging systems were developed, and currently the International Intraocular Retinoblastoma Classification and the TNM Classification are the preferred classification systems used in clinical practice, and thought to better predict the outcome for eyes treated with chemotherapy and focal laser treatment. ${ }^{3,16}$ In this study, Reese-Ellsworth classification was chosen to better compare all patients, since earlier cases were staged according to this method and there was no sufficient data to convert them to the International Intraocular Retinoblastoma Classification, used in more recent patients. Most unilateral retinoblastomas presented with advanced disease (57.6\% stage IV-V versus $15.1 \%$ stage I-III), whereas in bilateral retinoblastomas, patients were evenly distributed between stages I-III and IV-V. These results were similar to those described by Luna-Fineman et al in a review of retinoblastoma cases in five countries from Central America. ${ }^{17}$ The more advanced staging in unilateral retinoblastoma may be related to later diagnosis. This could be explained either by more obvious clinical presentation in bilateral retinoblastoma or by increased medical and parental awareness related to a positive familial history. It is difficult to determine the effect of this finding on the patients' survival rate due to the low mortality of retinoblastoma in this series. However, the more advanced stage of unilateral cases is important for the morbidity of this disease, since it may deprive the patient from the possibility of avoiding enucleation and achieving better vision survival.

Over the last few years, there has been a decrease in enucleation for retinoblastoma patients due to the development of more effective conservative treatment options. Despite this, enucleation remains an option in advanced intraocular disease with anterior chamber tumor invasion, iris neovascularization, secondary glaucoma, tumors occupying $>50 \%$ of vitreous volume, and tumors associated with hyphema or vitreous hemorrhage where the tumor characteristics cannot be visualized. ${ }^{1}$ In this series, enucleation was the most frequently performed treatment, particularly in unilateral retinoblastoma, which could be explained by the more advanced stage of disease in that group of patients.

Successful conservative treatment of retinoblastoma is the goal. However, conservative treatment options carry an important economic burden, related to the equipment, drugs, medical training, and inpatient care needed, as previously shown by Aziz et al. ${ }^{18}$ All the associated costs may make conservative treatment prohibitive in middle-income countries, and certainly do so in low-income countries. Cooperative strategies, such as the one presented involving the Ophthalmology Department of HSJ and the Centre Ophthalmic Jules Gonin, overcome these difficulties and level the standard of care between developed and developing countries.

The importance of an early diagnosis and the correct staging of retinoblastoma cannot be stressed enough to allow better timing for referral and the best treatment outcome. In fact, half of the eyes treated conservatively retained a

Table 5 Treatment of bilateral retinoblastoma between 1993 and 2012

\begin{tabular}{lllll}
\hline Retinoblastoma & $\begin{array}{l}\text { Frequency, } \\
\text { N }\end{array}$ & $\begin{array}{l}\text { Bilateral enucleation, } \\
\mathbf{N}(\%)\end{array}$ & $\begin{array}{l}\text { Unilateral enucleation + contralateral } \\
\text { conservative treatment,* N (\%) }\end{array}$ & $\begin{array}{l}\text { Conservative } \\
\text { treatment,* N (\%) }\end{array}$ \\
\hline Bilateral & 13 & $\mathrm{I}(7.7)$ & $8(61.5)$ & $4(30.8)$ \\
\hline
\end{tabular}

Note: *Conservative treatment options available: chemoreduction, thermochemotherapy, transpupillary thermotherapy, cryotherapy, brachytherapy, laser phototherapy (xenon and argon), targeted intra-arterial melphalan chemotherapy, and intravitreal injection of melphalan thermochemotherapy.

Abbreviations: \%, relative frequency; $\mathrm{N}$, absolute frequency. 
Table 6 Visual acuity in eyes submitted to conservative treatment

\begin{tabular}{lll}
\hline BCVA (decimal scale) & $\mathbf{N}$ & $\%$ \\
\hline 0.05 & $\mathrm{I}$ & 8.3 \\
0.08 & $\mathrm{I}$ & 8.3 \\
0.10 & 3 & 25.0 \\
0.30 & $\mathrm{I}$ & 8.3 \\
0.50 & $\mathrm{I}$ & 8.3 \\
0.60 & 2 & 16.7 \\
0.80 & 3 & 25.0 \\
Total & 12 & 100.0 \\
\hline
\end{tabular}

Note: Three patients with bilateral retinoblastoma were not able to cooperate for visual acuity measurement and were excluded.

Abbreviations: \%, relative frequency; BCVA, best corrected visual acuity; $\mathrm{N}$, absolute frequency.

best corrected visual acuity equal or better than $5 / 10$, which demonstrates the quality of life that can currently be expected in retinoblastoma patients who undergo successful conservative treatment.

\section{Conclusion}

Of 59 eyes with retinoblastoma treated, 18 were managed successfully with conservative treatment alone. There was only one death recorded during the follow-up period, and only one case with special educational needs. The two cases that developed secondary malignancies were treated and are currently in remission. To our knowledge, this is the first published report concerning retinoblastoma diagnosis, treatment, and follow-up in Portugal. The outcomes for our patients were similar to those expected in developed countries.

\section{Disclosure}

The authors declare no conflicts of interest in this work.

\section{References}

1. Mehta M, Seth S, Pushker N, et al. Retinoblastoma. Singapore Med J. 2012;53(2):128-135.

2. Kivelä $\mathrm{T}$. The epidemiological challenge of the most frequent eye cancer: retinoblastoma, an issue of birth and death. Br J Ophthalmol. 2009;93(9):1129-1131.
3. Dimaras H, Kimani K, Dimba EA, et al. Retinoblastoma. Lancet 2012;379(9824):1436-1446.

4. Abramson DH. Retinoblastoma in the 20th century: past success and future challenges the Weisenfeld lecture. Invest Ophthalmol Vis Sci. 2005;46(8):2683-2691.

5. Reese AB, Ellsworth RM. The evaluation and current concept of retinoblastoma therapy. Trans Am Acad Ophthalmol Otolaryngol. 1963;67:164-172.

6. Aerts I, Lumbroso-Le Rouic L, Gauthier-Villars M, Brisse H, Doz F, Desjardins L. Retinoblastoma. Orphanet J Rare Dis. 2006;1:31.

7. Gombos DS, Diba R. Estimating the incidence of retinoblastoma in Texas. Tex Med. 2005;101(7):70-72.

8. Abramson DH, Frank CM, Susman M, Whalen MP, Dunkel IJ, Boyd NW 3rd. Presenting signs of retinoblastoma. J Pediatr. 1998;132(3 Pt 1): 505-508.

9. Meel R, Radhakrishnan V, Bakhshi S. Current therapy and recent advances in the management of retinoblastoma. Indian J Med Paediatr Oncol. 2012;33(2):80-88.

10. Mallipatna AC, Sutherland JE, Gallie BL, Chan H, Héon E. Management and outcome of unilateral retinoblastoma. J AAPOS. 2009;13(6):546-550.

11. Rubenfeld M, Abramson DH, Ellsworth RM, Kitchin FD. Unilateral vs bilateral retinoblastoma. Correlations between age at diagnosis and stage of ocular disease. Ophthalmology. 1986;93(8):1016-1019.

12. Ray A, Gombos DS, Vats TS. Retinoblastoma: an overview. Indian $J$ Pediatr. 2012;79(7):916-921.

13. Gao YJ, Qian J, Yue H, Yuan YF, Xue K, Yao YQ. Clinical characteristics and treatment outcome of children with intraocular retinoblastoma: a report from a Chinese cooperative group. Pediatr Blood Cancer. 2011;57(7):1113-1116.

14. Nabie R, Taheri N, Fard AM, Fouladi RF. Characteristics and clinical presentations of pediatric retinoblastoma in North-western Iran. Int $J$ Ophthalmol. 2012;5(4):510-512.

15. Leander $\mathrm{C}, \mathrm{Fu} \mathrm{LC}$, Peña A, et al. Impact of an education program on late diagnosis of retinoblastoma in Honduras. Pediatr Blood Cancer. 2007;49(6):817-819.

16. Linn Murphree A. Intraocular retinoblastoma: the case for a new group classification. Ophthalmol Clin North Am. 2005;18(1):41-53.

17. Luna-Fineman S, Barnoya M, Bonilla M, Fu L, Baez F, RodríguezGalindo C. Retinoblastoma in Central America: report from the Central American Association of Pediatric Hematology Oncology (AHOPCA). Pediatr Blood Cancer. 2012;58(4):545-550.

18. Aziz HA, Lasenna CE, Vigoda M, et al. Retinoblastoma treatment burden and economic cost: impact of age at diagnosis and selection of primary therapy. Clinical Ophthalmol. 2012;6:1601-1606.
Clinical Ophthalmology

\section{Publish your work in this journal}

Clinical Ophthalmology is an international, peer-reviewed journal covering all subspecialties within ophthalmology. Key topics include: Optometry; Visual science; Pharmacology and drug therapy in eye diseases; Basic Sciences; Primary and Secondary eye care; Patient Safety and Quality of Care Improvements. This journal is indexed on

\section{Dovepress}

PubMed Central and CAS, and is the official journal of The Society of Clinical Ophthalmology (SCO). The manuscript management system is completely online and includes a very quick and fair peer-review system, which is all easy to use. Visit http://www.dovepress.com/ testimonials.php to read real quotes from published authors. 